\title{
Chromosome Pairing and Cytomixis in Safflower (Carthamus tinctorius L., Asteraceae) Cultivars
}

\author{
Masoud Sheidai ${ }^{1, *}$, Marjan Sotoode ${ }^{1}$ and Zahra Nourmohammadi ${ }^{2}$ \\ ${ }^{1}$ Shahid Beheshti University, GC, Faculty of Biological Sciences, Tehran, Iran \\ ${ }^{2}$ Biology Department, school of Basic Sciences, Science and Research Branch (SRBIAU), \\ Islamic Azad University, Poonak, Tehran, Iran
}

Received January 13, 2009; accepted February 7, 2009

\begin{abstract}
Summary Cytogenetic studies concerning karyotype and meiotic analyses were performed in thirty-seven cultivars of $C$. tinctorius grown in Iran. All the cultivars showed $2 n=2 x=24$ chromosome number having meta and sub-meta centric chromosomes ranging in size from 1.55 to $4.63 \mu \mathrm{m}$. The cultivars studied differed significantly in the size of chromosomes and in karyotype formulae indicating the occurrence of quantitative and qualitative changes in their chromosomes. Meiotic analysis showed the occurrence of post pachytene diffuse stage, mostly bivalent formation in metaphase and also the occurrence of quadrivalents due to translocations in some of the cultivars studied. Meiotic abnormalities like chromosomes stickiness, laggard formation, multipolar cells and cytomixis occurred in some of the cultivars leading to pollen sterility and polyploid pollen formation. Grouping of the cultivars based on cytogenetic data showed their genetic differences.
\end{abstract}

Key words Chiasma frequency, Meiotic abnormalities, Safflower.

The genus Carthamus L. (Asteraceae) is comprised of diploid, autopolyploid and allopolyploids species distributed mainly in the east of the Mediterranean basin while some of its species (C. creticus L., C. lanatus L. and C. leucocaulos Sibth. \& Sm.) colonizing other Mediterranean regions, including Argentina, Australia, California and South Africa, where they can be invasive (Knowles and Ashri 1958, Ashri and Knowles 1960, Hanelt 1963, Estilai 1977, Estilai and Knowles 1978, 1980). Carthamus tinctorius L. (safflower) is widely cultivated for a variety of uses including oil extraction (Hanelt 1963) and as a saffron substitute.

Controversies exists about the number of species and also taxonomic delimitation of the genus Carthamus. Different approaches including morphology, cytology, experimental hybridizations, isozyme analysis as well as molecular studies have been performed to resolve the taxonomic problem of the genus and also to reveal the polyploidy nature of the Carthamus species (Ashri and Knowles 1960, Harvey and Knowles 1965, Khidir and Knowles 1970a, b, Efron et al. 1973, Vilatersana et al. 2000, 2005, Garnatje et al. 2006).

Knowles (1958) considered 25 species to occur in the genus Carthamus, while according to recent molecular studies performed by Vilatersana et al. (2005), the genus Carthamus includes 18 species. Hanelt (1963) based on morphological and cytological studies divided the genus Carthamus into five sections while, Ashri (1957) and latter on Ashri and Knowles (1960) based on different chromosome numbers obtained divided the genus into four sections having the species with $2 n=24,20,44$ and 64 distributed in these sections. Estilai (1971) found new chromosome number of $2 n=32$ and suggested the fifth section to be added to previous sections of Ashri and Knowles (1960). However, based on molecular studies Vilatersana et al. (2005) distributed the Carthamus species in two sections of Carthamus and Atractylis Rchb. Section Atractylis includes a group of allopolyploid species.

*Corresponding author, e-mail: msheidai@yahoo.com 
Cytogenetic studies indicate the occurrence of three basic chromosome numbers of $x=10,11$ and 12 in the genus Carthamus (Garnatje et al. 2006).

Safflower (Carthamus tinctorius L) is a diploid species $(2 n=2 x=22)$ and is considered as an important oil crop with a high economic value which can be hybridized with other Carthamus species producing allopolyploid plants. This species is distributed from the Middle East through Iran and Pakistan to India. Various cytogenetic studies have been performed on safflower cultivars throughout the world (Carapetian and Rupet 1977, Pillai et al. 1981a, b, Jayaramu and Chatter 1986, Singh et al. 1981, Kumar et al. 1984), while such studies are totally lacking in Iran. Several safflower cultivars are cultivated in Iran and at present cytogenetic, genetic and agronomic evaluations of these cultivars are in hand. The present report considers karyotype analysis, meiotic chromosome pairing and segregation as well as occurrence of B-chromosomes and unreduced gamete formation in these cultivars for the first time.

\section{Materials and methods}

Karyotype and meiotic studies were performed in thirty-seven cultivars of $C$. tinctorius grown in Iran (Tables 1 and 2). Seeds and flower buds were obtained from the safflower germplasm of the Seed and Seedling Research center, Karaj, Iran. For karyotype study, freshly grown root tips were collected from the germinated seed of at least ten randomly selected plants in each species, pretreated with $0.002 \mathrm{~mol} 8$-hydroxyquinolin $(2-2.5 \mathrm{~h})$ and fixed in ethanol:acetic acid $(3: 1)$ for $24 \mathrm{~h}$. The fixed tips were then washed thoroughly in distilled water and macerated in $60^{\circ} \mathrm{C} 1 \mathrm{~N} \mathrm{HCl}$ for about $5 \mathrm{~min}$. The squash technique was used for cytological studies with $2 \%$ aqueous aceoorcein as the stain. The somatic chromosome number and karyotype details were studied in at least 5 well-prepared metaphase plates. The chromosomes were photographed by a digital camera and measured by Image Tools 3 software (Sheidai and Rashid 2007).

The chromosomes were identified according to Levan et al. (1964), the karyotype symmetry was determined according to Stebbins (1971), while other karyotype parameters like haploid total chromosome length (Total sum of the size of the chromosomes by using only one chromosome from each pair), mean chromosome length (Total haploid chromosome length/number of chromosome pairs), total form percentage ( $\mathrm{TF} \%=$ Sum of short arms of the chromosomes/Total chromosome length) and coefficient of variation $(\mathrm{CV})$ of the chromosome size were determined (Sheidai and Jalilian 2008).

Meiotic studies were performed on young flower buds collected using minimum 100 metaphase/diakinesis pollen mother cells (PMCs) and 500 anaphase and telophase cells for data collection (Sheidai and Rashid 2007). Pollen satiability as a measure of fertility was determined by staining minimum 1000 pollen grains with $2 \%$ acetocarmine: $50 \%$ glycerin $(1: 1)$ for about 30 min. Complete pollens which were stained were taken as fertile, while incomplete, shrunken pollens with no stain were considered as infertile (Sheidai and Rashid 2007).

For karyotype analyses, in order to reveal significant difference, the analysis of variance (ANOVA) followed by the least significant difference test (LSD) were performed on the size of chromosomes, size of the long arms and size of the short arms as well as arms ratio among the species and populations studied (Sheidai and Jalilian 2008). Pearson coefficient of correlation was determined among karyotype parameters. Principal components analysis (PCA) was performed on karyotype feature to identify the most variable karyotype characters among the cultivars studied (Sheidai and Jalilian 2008).

For meiotic analyses, $\chi^{2}$ test was performed to detect a significant difference in chiasma frequency and chromosome pairing as well as meiotic abnormalities (Sheidai and Rashid 2007). Pearson coefficient of correlation was performed among meiotic abnormalities.

In order to detect the significant difference between potential unreduced pollen grains 
Table 1. Karyotype features of C. tinctorius cultivars studied

\begin{tabular}{lllllllll}
\hline \hline Cultivar & \multicolumn{1}{c}{ Origin } & TL & L & S & LS & X & TF & KF \\
\hline Acetaria & F. A. O. & 57.72 & 4.63 & 2.13 & 2.17 & 4.81 & 37.00 & $4 \mathrm{~m}+8 \mathrm{sm}$ \\
Syrian & Syria & 51.24 & 3.43 & 1.66 & 2.07 & 4.27 & 38.00 & $8 \mathrm{~m}+4 \mathrm{sm}$ \\
Dinjer & ICARDA & 53.40 & 4.11 & 1.66 & 2.48 & 4.45 & 36.00 & $6 \mathrm{~m}+6 \mathrm{sm}$ \\
KJ & Karaj & 58.80 & 3.76 & 1.90 & 1.98 & 4.90 & 41.00 & $10 \mathrm{~m}+2 \mathrm{sm}$ \\
Zarghan 2 & Zarghan & 62.40 & 4.23 & 1.98 & 2.14 & 5.20 & 40.00 & $11 \mathrm{~m}+1 \mathrm{sm}$ \\
Zarghan & Zarghan & 59.40 & 4.00 & 1.61 & 2.48 & 4.95 & 42.00 & $11 \mathrm{~m}+1 \mathrm{sm}$ \\
S66041 & Urmiya & 47.64 & 3.21 & 1.61 & 1.99 & 3.97 & 40.00 & $10 \mathrm{~m}+2 \mathrm{sm}$ \\
LRV5567 & Urmiya & 57.75 & 3.63 & 2.21 & 1.64 & 4.81 & 41.00 & $11 \mathrm{~m}+1 \mathrm{sm}$ \\
CH1353 & F. A. O & 58.92 & 3.66 & 2.00 & 1.83 & 4.91 & 40.00 & $11 \mathrm{~m}+1 \mathrm{sm}$ \\
Varamin259 & Varamin & 64.80 & 4.13 & 1.76 & 2.35 & 5.40 & 40.00 & $12 \mathrm{~m}$ \\
Rinconada & F. A. O & 66.96 & 4.36 & 2.43 & 1.79 & 5.58 & 39.00 & $10 \mathrm{~m}+2 \mathrm{sm}$ \\
S646 & Urmiya & 58.44 & 3.85 & 2.00 & 1.93 & 4.87 & 41.00 & $12 \mathrm{~m}$ \\
S648 & Iran & 57.84 & 3.81 & 1.91 & 1.99 & 4.82 & 40.00 & $10 \mathrm{~m}+2 \mathrm{sm}$ \\
LRV5565 & Varamin & 55.80 & 3.66 & 1.83 & 2.00 & 4.65 & 42.00 & $12 \mathrm{~m}$ \\
697 & Urmiya & 60.48 & 4.00 & 2.18 & 1.83 & 5.04 & 39.00 & $9 \mathrm{~m}+3 \mathrm{sm}$ \\
CH65 & F. A. O & 62.64 & 4.48 & 2.26 & 1.98 & 5.22 & 40.00 & $11 \mathrm{~m}+1 \mathrm{sm}$ \\
3147 & Iran & 53.40 & 3.48 & 2.00 & 1.74 & 4.45 & 41.00 & $11 \mathrm{~m}+1 \mathrm{sm}$ \\
S7V60 & Azarbayejan & 57.84 & 3.76 & 2.00 & 1.88 & 4.82 & 41.00 & $10 \mathrm{~m}+2 \mathrm{sm}$ \\
LRV5120 & Varamin & 49.80 & 3.43 & 1.83 & 1.87 & 4.15 & 38.00 & $9 \mathrm{~m}+3 \mathrm{sm}$ \\
LRV5111 & Varamin & 49.20 & 3.26 & 1.55 & 2.10 & 4.10 & 41.00 & $11 \mathrm{~m}+1 \mathrm{sm}$ \\
\hline
\end{tabular}

Abbreviations: TL. Total haploid chromosome length $(\mu \mathrm{m}), \mathrm{L}$. Size of the longest chromosome $(\mu \mathrm{m}), \mathrm{S}$. Size of the shortest chromosome $(\mu \mathrm{m}), \mathrm{L} / \mathrm{S}$. Ratio of the longest to shortest chromosome, X. Mean chromosome length $(\mu \mathrm{m}), \mathrm{CV}$. Coefficient of chromosome size variation, $\mathrm{TF} \%$. Total form percentage.

and the normal (reduced pollens), as well as meiotic characteristics of the cells possessing B-chromosomes (Bs) and those devoid of Bs, $t$-test was performed. Statistical analyses used SPSS ver. 9 (1998) and DARwin ver. 5.0.155 (2006) software.

In order to group the species studied based on similarity in their karyotype features as well as meiotic characteristics, UPGMA (Unweighted Paired Group with Arithmetic Average) and Neighbor Joining (NJ) clustering methods as well as ordination based on principal coordinate analysis (PCO) were performed. NTSYS Ver. 2.02 (1998) was used for clustering and PCO analyses. Standardized karyotype data $($ mean $=0$, variance $=1)$ were used to determine taxonomic distance among the species which were used in clustering (Sheidai and Jalilian 2008). Cophenetic correlation was estimated to determine the goodness of the fit of the clusters to the original data (Sheidai and Jalilian 2008).

\section{Results and discussion}

\section{Karyotype features}

Details of karyotype analysis in the $C$. tinctorius cultivars studied is presented in Table 1 and Fig. 1. All the cultivars studied showed $2 n=2 x=24$ supporting the earlier reports (Estilai and Knowels 1976, Estilai 1977, Carapetian and Rupet 1977). The chromosomes were metacentric (m) and sub-metacentric (sm) ranging in size from 1.55 to $4.63 \mu \mathrm{m}$ in the cultivars studied (Table 1). The size of the longest chromosome varied from $3.21 \mu \mathrm{m}$ in the cultivar S66041 to $4.63 \mu \mathrm{m}$ in the cultivar Acetaria (Table 1), while the size of shortest chromosomes varied from $1.55 \mu \mathrm{m}$ in the cultivar LRV5111 to $2.21 \mu \mathrm{m}$ in the cultivar LRV5567 (Table 1). Pillai et al. (1981a) studied safflower cultivars grown in India reporting the size of chromosomes to vary from 2.05 to $3.52 \mu \mathrm{m}$ with the average of $2.90 \mu \mathrm{m}$. The arm ratios ranged from 1.25 to 4.50 . The centromere was mostly median to submedian, being subterminal in two pairs of chromosomes. There were three 

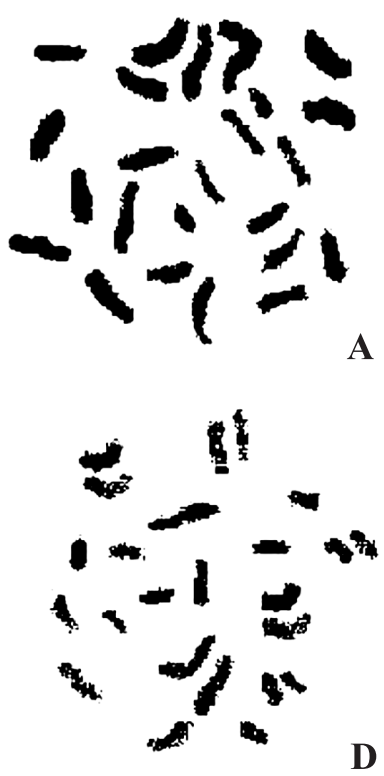

D

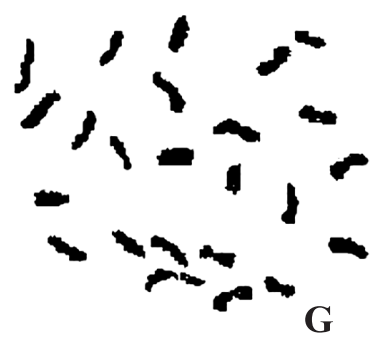

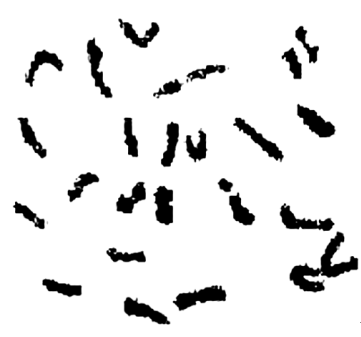

B

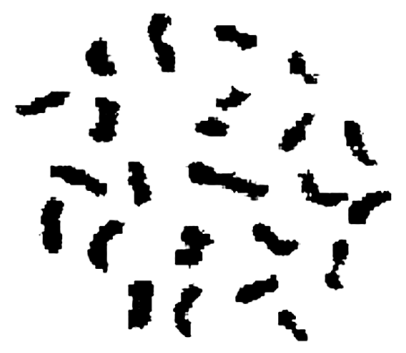

C

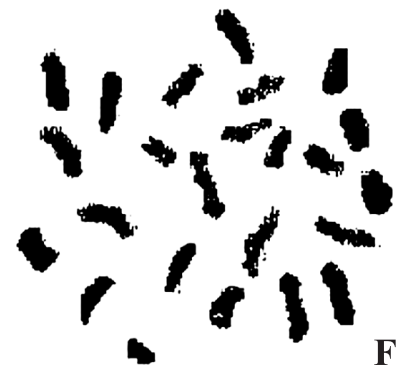

Fig. 1. Representative somatic metaphase cells in C. tinctorius cultivars studied. A. Metaphase cell showing $2 n=24$ in the cultivar Acetaria. B. Metaphase cell showing $2 n=24$ in the cultivar Varamin 259. C. Metaphase cell showing $2 n=24$ in the cultivar Zarghan. D. Metaphase cell showing $2 n=24$ in the cultivar CH-1353. E. Metaphase cell showing $2 n=24$ in the cultivar Zarghan 259. F. Metaphase cell showing $2 n=24$ in the cultivar S646. G. Metaphase cell showing $2 n=24$ in the cultivar 697 . Scale $\mathrm{bar}=10 \mu \mathrm{m}$.

pairs of satellite-chromosomes.

The highest haploid total chromosome length as well as mean chromosome length occurred in the cultivar Rinconada (66.96 and $5.58 \mu \mathrm{m}$ respectively), while the lowest value of the same occurred in the cultivar S66041 (47.64 and $3.97 \mu \mathrm{m}$ respectively). The highest value of chromosomes size variation $(\mathrm{CV}=17.97)$ occured in the cultivar Syrian while the lowest CV (5.00) occured in the cultivar 697 (Table 1).

The ANOVA followed by LSD tests revealed a significant differences $(p<0.05)$ for total size of the chromosomes, size of the short arms and the long arms among the species and populations studied, indicating the occurrence of quantitative genomic changes in the cultivars studied. Studies performed by Garnatje et al. (2006) also showed difference in the DNA content (2C value) of different $C$. tinctorius cultivars ranging from $2.68-2.79 \mathrm{pg}$.

Pearson correlation determined among karyotype features showed a significant positive correlation between total and mean chromosome length with both longest as well as shortest chromosomes $(r>0.65, p<0.01)$. Therefore the significant quantitative change in the chromatin material has been occurred in the size of both chromosomes arms during the species diversification. 


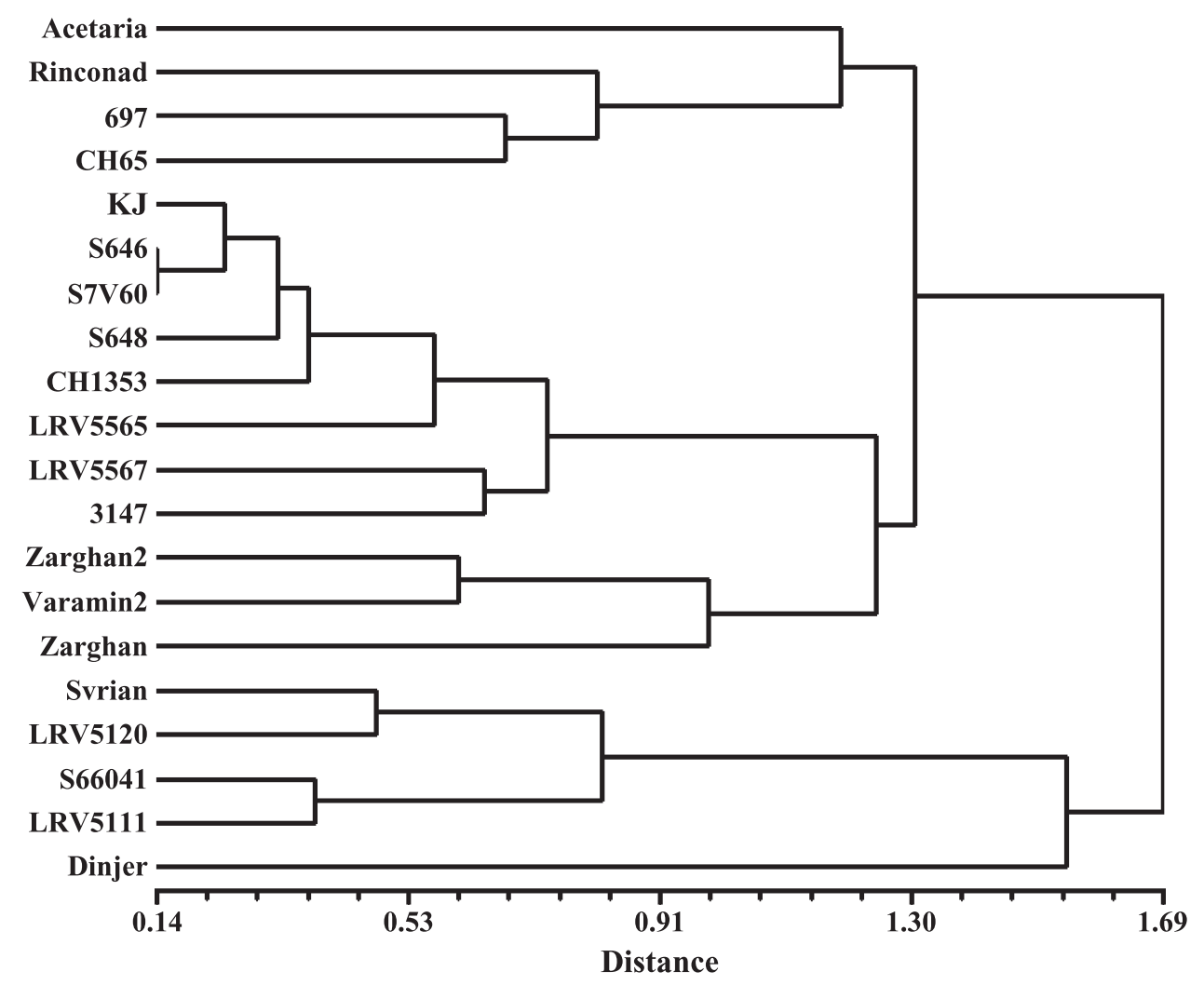

Fig. 2. UPGMA dendrogram of karyotype data.

C. tinctorius cultivars studied differed in their karyotype formulae (Table 1) indicating the occurrence of structural changes in their chromosomes (Table 1). The occurrence of heterozygote translocations observed in C. tinctorius cultivars (discussed in the followig paragraphs) supports such suggestion.

Total form percentage (TF\%) varied from 36 in Dinjer cultivar to 42 in the cultivars Zarghan and LRV5565 (Table 1); a higher value of TF\% indicates the presence of relatively more symmetrical karyotype. C. tinctorius cultivars were placed in 1A, 2A, 1B and 2B classes of Stebbins karyotype symmetry which are considered relatively primitive in this system.

PCA analysis (data not given) shows that the first 2 components comprise about $84 \%$ of the total variation. In the first component with about $75 \%$ of total variance, the mean chromosome length, size of the short arms and long arms as well as total length of the chromosomes are the most variable characters $(r>0.90)$, supporting the results of ANOVA stated earlier. In the second factor with about $9 \%$ of total variance, the ratio of the long arm to the short arm of the chromosomes and $\mathrm{TF} \%$ are most variable characters $(r>0.80)$, supporting our earlier suggestion about the role of qualitative changes in the cultivar diversification.

Different clustering methods and ordination of the cultivars based on PCA analysis of karyotype data produced similar results and the highest cophenetic correlation was obtained for UPGMA dendrogram ( $r=0.8$ ), therefore UPGMA dendrogram is discussed bellow (Fig. 2).

In general 3 major clusters are formed. The cultivars Acetaria, Rinconada, CH-65 and 697 comprise the first major cluster of which, the first three cultivars have been obtained from F. A. O. The cultivar Acetaria shows more karyotype differences with the other cultivars and is placed far from them. The cultivars Dinjer, LRV-5111, LRV-5120 and S66041 comprise the third major clus- 


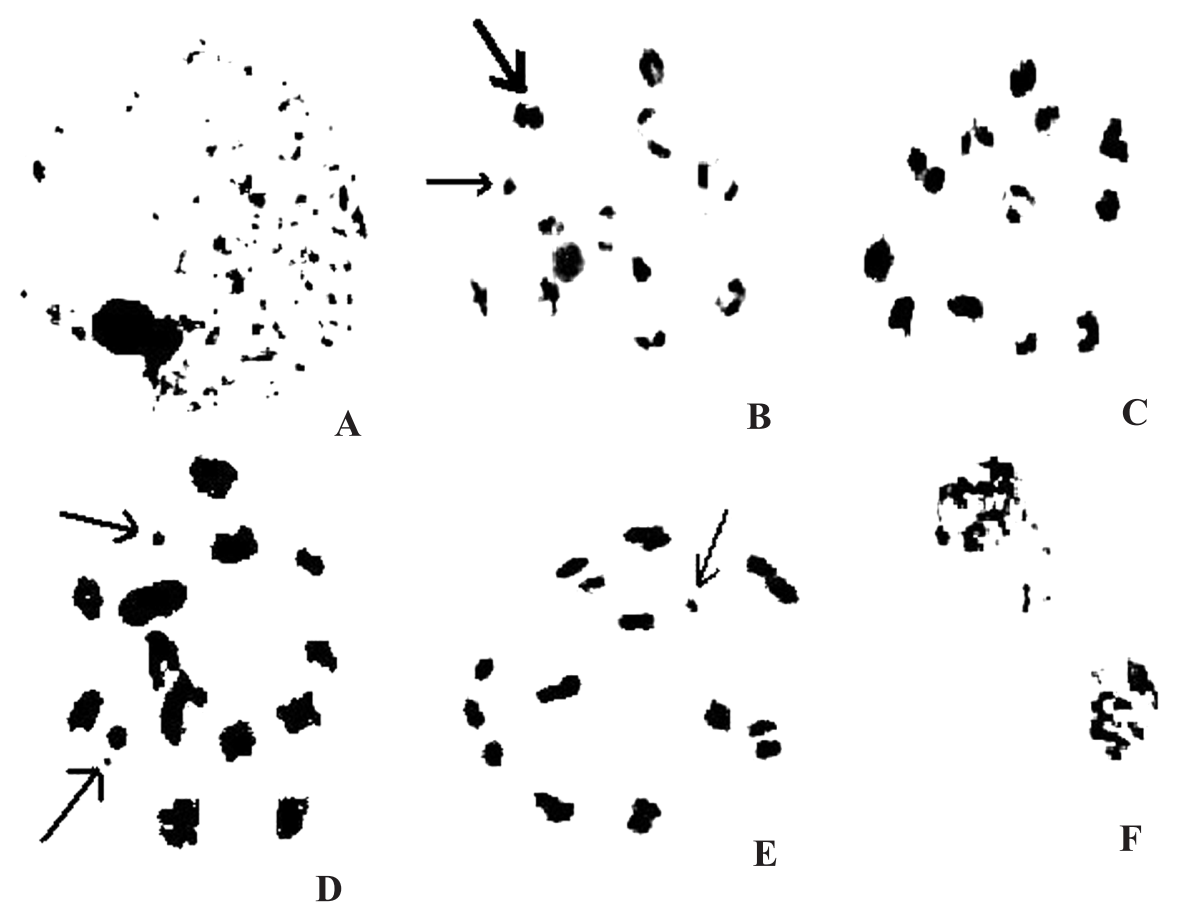

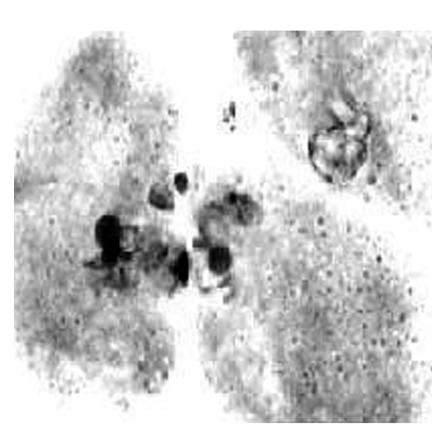

G

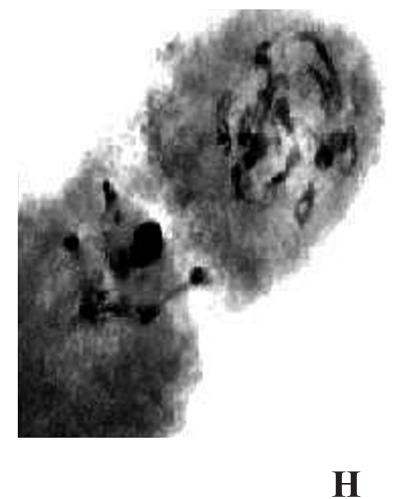

H

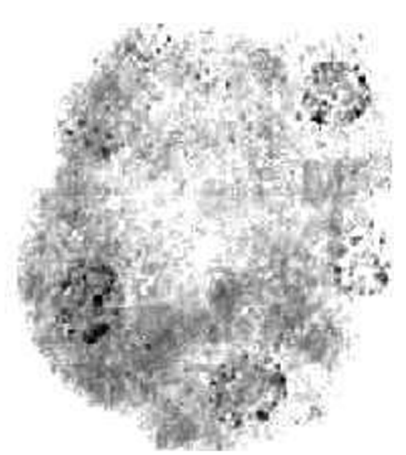

I

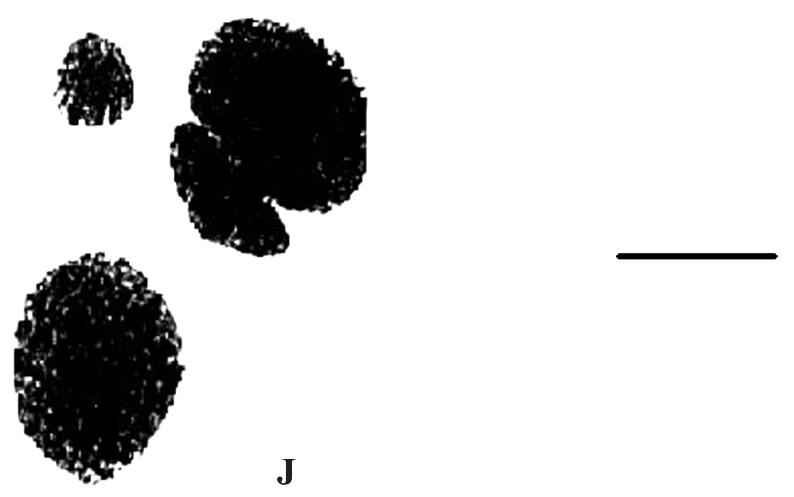


Table 2. Meiotic characteristics of $C$. tinctorius cultivars studied

\begin{tabular}{lllllllrrr}
\hline \hline Culivar & Origin & RD & RB & TX & IX & TOX & I & IV \\
& Varamin & 4.33 & 7.64 & 15.60 & 2.91 & 18.50 & 2.00 & .00 \\
IL_111 & Varamin & 3.96 & 7.96 & 17.25 & 2.11 & 19.36 & 4.00 & 1.00 \\
LRE_51 & Varamin & 3.40 & 8.61 & 18.70 & 1.65 & 20.35 & .00 & .00 \\
LRE_36 & Varamin & 6.39 & 5.61 & 14.92 & 1.86 & 16.78 & .00 & .00 \\
LRE_34 & Varamin & 3.98 & 7.98 & 16.42 & 2.70 & 19.12 & 2.00 & .00 \\
LRE_20 & Varamin & 4.30 & 7.70 & 16.87 & 1.93 & 18.80 & .00 & .00 \\
LRE_31 & Varamin & 4.02 & 7.96 & 18.58 & 1.18 & 19.76 & 2.00 & .00 \\
LRE_29 & Arak & 6.00 & 4.80 & 15.60 & 2.50 & 18.10 & 1.00 & .10 \\
Arak2811 & Arak & 7.00 & 3.20 & 15.40 & 2.30 & 17.70 & .20 & 3.00 \\
TN7733 & Arak & 6.90 & 3.80 & 16.10 & 1.50 & 17.60 & .30 & .50 \\
TN7734 & Arak & 8.10 & 3.00 & 14.66 & 1.38 & 16.50 & .50 & .05 \\
TN7735 & Arak & 7.70 & 3.50 & 15.00 & 2.30 & 17.30 & .60 & .10 \\
TN7736 & Arak & 8.10 & 2.50 & 14.50 & 2.30 & 16.80 & .50 & .20 \\
TN7737 & Arak & 7.10 & 4.10 & 17.20 & 3.60 & 18.10 & .60 & .10 \\
TN7738 & Arak & 8.10 & 3.50 & 14.90 & 1.40 & 16.30 & .30 & .00 \\
TN7739 & Arak & 6.70 & 4.30 & 16.10 & 2.60 & 18.70 & .30 & .00 \\
TN7740 & Arak & 8.40 & 3.80 & 16.60 & 2.00 & 18.60 & .40 & .20 \\
TN7741 & Arak & & & & & & & & \\
\end{tabular}

Abbreviations: $\mathrm{RD}=$ Mean number of rod bivalents, $\mathrm{RB}=$ Mean number of ring bivalents, $\mathrm{TX}=$ Mean number of terminal chiasmata, $I X=$ Mean number of intercalary chiasmata, $T O X=$ Mean number of total chiasmata, $I=$ Mean number of univalents, IV=Mean number of quadrivalents.

ter, while the other cultivars are placed in the second major cluster. The cultivar Dinjer shows karyotype differences with the others and is placed far from the other cultivars.

It seems that the grouping obtained is not related to the geographical origin of the cultivars as for example cultivars from Urmiya are distributed in all 3 major clusters formed, the same is true for cultivars obtained from Varamin which have been distributed in the second and third major clusters. Therefore karyotype results shows partly genetic differences of the cultivars studied which may be used for planning hybridization in safflower cultivars of Iran.

\section{Chromosome pairing and segregation}

Meiotic analysis of the $C$. tinctorius cultivars showed the occurrence of post pachytene diffuse stage (Fig. 3A). Diffusion may be of complete type in which the whole chromosomes undergo decondensation or it may be partial in which some parts of the genome decondense. The present study showed the occurrence of the partial diffusion in C. tinctorius for the first time.

Various reasons have been suggested for the occurrence of the diffuse stage. These are: high synthetic activity analogous to the lampbrush stage in the amphibian oocyte, shedding of the lateral elements in the synaptonemal complex, the post pachytene elimination or modification of histone proteins and the meiotic arrest to withstand the adverse environmental conditions (Sheidai and Inamdar 1991). However the exact reason for the occurrence of the diffuse stage in C. tinctorius cultivars is not known.

Fig. 3. Representative meiotic cells in C. tinctorius cultivars studied. A. Post pachytene diffuse stage in cultivar LRE20. B. Metaphase cell showing $n=11$ (thin arrow indicates B-chromosome while thicker arrow indicates a quadrivalent) in the cultivar LRE-51. C. Metaphase cell showing $n=11$ in the cultivar LRE-36. D. Metaphase cell showing extra chromosomes $(n=14)$ in the cultivar LRE-29 (arrow indicates B-chromosome). E. Metaphase cell showing $n=11$ in the cultivar (arrow indicates B-chromosome) in the cultivar IL-111. F. Anaphase-I meiocyte showing laggard chromosomes in the cultivar Arak2811. G, H. Meiocytes showing cytomixis in the cultivars LRE-31 and LRE-20 respectively. I. Meiocyte showing multipolar cells in the cultivar LRE-51. J. Pollen grains with variable sizes in the cultivar LRE-31. Scale bar $=10 \mu \mathrm{m}$. 
Data with regard to the chiasma frequency and distribution as well as chromosome pairing are provided in Table 2. C. tinctorius cultivars showed $2 n=2 x=24$ chromosome number (Fig. 3B-E). The highest value of total and terminal chiasmata occurred in LRE-36 cultivar (20.35 and 18.70 respectively), while the lowest value of the same occurred in TN-7735 and TN-7737 (16.50 and 14.50 respectively). The cultivar TN-7738 showed the highest value of intercalary chiasmata (3.60) and cultivar LRE-29 showed the lowest value of the same (1.18). The cultivar LRE-36 showed the highest mean value of ring bivalents (8.61), while TN-7737 showed the lowest value for the same (2.50).

Although C. tinctorius cultivars studied are diploid and are expected to form only bivalents in metaphse of meiosis-I, cultivars LRE-51 and TN-7733 formed 1-2 quadrivalents (Table 2), indicating the occurrence of heterozygote translocations between two pairs of chromosomes. Such chromsomal structural changes may increase the amount of the genetic variability in the gametes by forming new genetic linkage groups which may be used for an adaptation to adverse environmental conditions.

Pillai et al. (1981b) could establish ten translocation homozygote lines in safflower. The chromosomes involved in each interchange homozygote were identified through the karyotype analysis by comparing the relative chromosome length and the arm the ratio with that of the standard line 'I.C. 11842'. The chromosomes which were involved in interchang were identified as 6-8, 1-3, 3-12, 3-10, 3-6, 4-6, 4-8, 3-8 and 5-9 in the lines obtained. Moreover, chromosome 3-(satellitechromosome) was involved in 6 of the 10 translocations.

Singh et al. (1981) also isolated sixty-two translations in the $\mathrm{M}_{1}$ generation of gamma-irradiated populations of $C$. tinctorus. Most of the simple translocations were induced at 30 and $45 \mathrm{kR}$, whereas the high dose of $60 \mathrm{kR}$ produced complex interchanges which failed to produce seed. The pollen sterility of the interchange heterozygotes ranged from 1 to $99.6 \%$ with an average of $53.76 \%$; 10 of the translocation heterozygotes showed pollen sterility comparable to the standard normal. The interchange heterozygotes at metaphase I had characteristic chain and ring multivalents, mostly quadrivalents. Chain configurations were in excess of the rings in most of the translocations and the alternate orientation of the quadrivalents was most common.

ANOVA test performed on the chisma frequency and the chromosomes association showed a significant difference among the cultivars studied indicating their genetic differences. Variation in the chiasma frequency and localization is genetically controlled and has been reported in populations of different species (Rees and Jones 1977). Such a variation in the species and populations with the same chromosome number is considered as a means for generating new forms of recombination influencing the variability within natural populations in an adaptive way (Rees and Jones 1977).

Different clustering methods performed on meiotic characteristics produced similar results, therefore UPGMA dendrogram is discussed bellow (Fig. 4). In general two major clusters are produced. The cultivar IL-111 and other LRE cultivars form the first major cluster, while the cultivar Arak-2811 and other cultivars of TN comprise the second major clusters. The cultivars TN7733 and TN7738 differ in their meiotic characteristics and stand far from the other TN cultivars. separation of LRE and TN cultivars partly indicates their genetic differences.

\section{Meiotic abnormalities}

The occurrence of laggard chromosomes and chromosome stickiness were observed in the cultivars IL-111, LRE-131, LRE-36 and LRE-151 (Fig. 3F-I). The sticky chromosomes occurred from early stages of prophase to the final stages of meiosis. The number of chromosomes involved in stickiness varied from two to many forming a complete clumping of the chromosomes. The highest percentage of anaphase-I laggards (8.70) and chromosome stickiness (2.22) occurred in the cultivar LRE-36.

Multipolar cells were observed (Fig. 3I) in the cultivars IL-111, LRE-131, LRE-36 and LRE- 
151 possibly due to spindle abnormalities. Carapetian and Rupert (1977) while studying male sterile plants of safflower also reported the occurrence of multipolar cells and chromosome stickiness during microsporogenesis.

The spindle apparatus is normally bipolar and acts as a single unit, playing a crucial role in the chromosome alignment during metaphase. Any distortion or breakage in the spindle may result in random sub-grouping of the chromosomes which function independently (Nirmala and Rao 1996). In several instances spindle abnormalities have led to the production of aneuploid gametes for example in polyploidy hybrids and derivatives of Aegilops $\times$ Triticum hybrids, amphiploid Triticineae, amphiploids of Solanum hybrids, etc. Different reasons have been suggested for the occurrence of spindle abnormalities including: duality of nucleus in foreign cytoplasm, environmental influence and the disharmonious gene interaction (Nirmala and Rao 1996).

\section{Cytomixis}

The chromatin/chromosome migration occurred in different directions from early prophase to telophase-II in C. tinctorius cultivars studied (Fig. 3G, H). Several metaphase/diakinesis cells in these species possessed extra or missing chromosomes showing aneuploid condition (Fig. 3D). The migration of chromatin material among the adjacent meiocytes occurs through cytoplasmic connections originating from the pre-existing system of plasmodesmata formed within the tissues of the anther. The plasmodesmata become completely obstructed by the deposition of callose, but in some cases they still persist during meiosis and increase in size, forming conspicuous inter-meiocyte connections or cytomictic channels that permit the transfer of chromosomes (Falistocco et al. 1995). Cytomixis is considered to be of less evolutionary importance but it may lead to the production of aneuploid plants with certain morphological characteristics or produce unreduced gametes (DíazLifante et al. 1992). Unreduced gamete formation is of evolutionary importance leading to the production of plants with higher ploidy levels. Cytomixis by producing aneuploid pollen grains may also be responsible for the reduction in pollen fertility of the $C$. tinctorius cultivars studied. This is the first report on the occurrence of cytomixis in safflower.

$\chi^{2}$ test showed a significant difference $(p<0.05)$ for the percentage of chromosome stickiness and laggard chromosomes as well as cytomictic and multipolar cells formed among the species and populations studied. Genetic and environmental factors as well as the genomic-environmental interaction have been considered as the reason for chromosome stickiness in different plant species (Nirmala and Rao 1996).

The pearson coefficient of correlation determined among meiotic abnormalities showed a significant positive correlation between chromosomes stickiness and the laggard chromosome formation as well as the multipolar cell formation $(r>0.84, p<0.001)$. Cytomixis was also significantly correlated to the number of disorganised chromosomes $(r=0.76, p<0.05)$.

Meiotic abnormalities mentioned above may lead to the formation of abnormal tetrads and aneuploid as well as unreduced $(2 n)$ pollen grains (Nirmala and Rao 1996). Pollen fertility ranged from $90.00-99.00 \%$ in the cultivars studied. A little reduction in pollen fertility observed may be due to meiotic abnormalities obtained. Moreover pollen grains with variable sizes (possibly polyploid pollen grains) were observed along with smaller (normal) pollen grains in the cultivars LRE36, LRE-51 and IL-111 (Fig. 3J). The occurrence of unreduced ( $2 n)$ pollen grains has been reported in the gamma irradiated $C$. tinctorius cultivars due to meiotic irregularities including anaphase disturbances (Kumar et al. 1984), but not in natural populations of this species.

\section{B-chromosomes}

B-chromosomes (Bs) of 0-1 were observed in the cultivars IL-111, LRE-20, LRE-36 and LRE-151 (Fig. 3B, D, E). The Bs observed were much smaller than the A-chromosomes, round in shape and did not pair with the A-chromosomes. B-chromosomes are accessory chromosomes oc- 


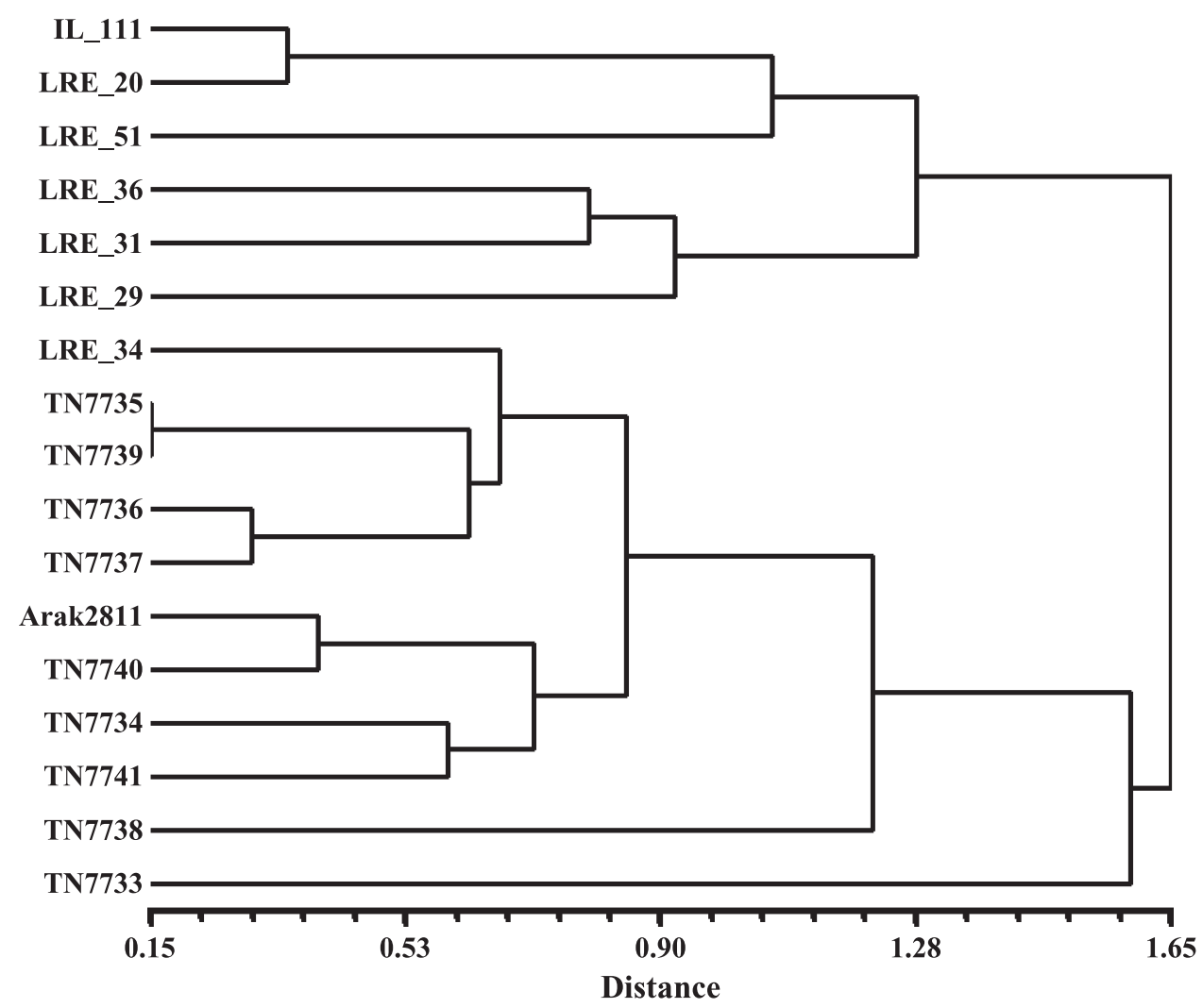

Fig. 4. UPGMA dendrogram of meiotic data.

curring in more than 1300 species of Plants and almost 500 species of animals (Camacho et al. 2000).

The B-chromosomes when present in high number affect negatively the growth and vigor of the plants, while in low number may benefit the plant possessing them. T-test analysis of the chiasma frequency and chromosomes pairing showed a significant increase in the mean number of total and terminal chiasmata as well as ring bivalents $(p<0.01)$ in the cultivar LRE-36, while no significant difference was observed between the cells having Bs and those devoid of Bs in the other cultivars. A significant change in the chiasma frequency may bring about more genetic variability in the gametes to be used in the next generation. To our knowledge this is the first report on the occurrence of B-chromosomes in C. tinctorius.

\section{References}

Ashri, A. 1957. Cytogenetics and morphology of Carthamus L. species and their hybrids. Ph. D. Thesis, Univ. Calif., Davis. Ashri, A. and Knowles, P. F. 1960. Cytogenetics of safflower (Carthamus L.) species and their hybrids. Agron J. 52: 11-17. Camacho, J. P. M., Sharbel, T. F. and Beukeboom, L. W. 2000. B-chromosome evolution. Philos. Trans. R. Soc. Lond., B, Biol. Sci. 355: 163-178.

Carapetian, J. and Rupert, E. A. 1977. Meiotic irregularities caused by interacting sterility genes in cultivated safflower (Carthamus tinctorius). Can. J. Genet. Cytol. 19: 103-109.

Díaz Lifante, Z., Luque, T. and Santa Barbara, C. 1992. Chromosome numbers of plants collected during Iter Meditranium II in Israel. Bocconea 3: 229-250.

Efron, Y., Peleg, M. and Ashri, A. 1973. Alcohol dehydrogenase allozymes in the safflower genus Carthamus. Biochem. 
Genet. 9: 299-308.

Estilai, A. 1971. Cytogenetic studies of Carthamus species (Compositae) with eleven pairs of chromosomes. Ph. D. Thesis., Univ., Calif., Davis.

- 1977. Interspecific hybrids between C. tinctorius and C. alexandrinus. Crop Sci. 17: 800-802.

— and Knowles, P. F. 1976. Cytogenetic studies of Carthamus divaricatus with eleven pairs of chromosomes and its relationship to other Carthamus species (Compositae). Am. J. Bot. 63: 771-782.

- and - 1978. Relationship of Carthamus leucocaulos to other Carthamus species (Compositae). Can. J. Genet. Cytol. 20: $221-233$.

— and - 1980. Aneuploids in safflower. Crop Sci. 20: 516-518.

Falistocco, E., Tosti, T. and Falcinelli, M. 1995. Cytomixis in pollen mother cells of diploid Dactylis, one of the origins of $2 n$ gametes. J. Hered. 86: 448-453.

Garnatje, T., Garcia, S., Vilatersana, R. and Vallès, J. 2006. Genome Size Variation in the Genus Carthamus (Asteraceae, Cardueae): Systematic Implications and Additive Changes During Allopolyploidization. Ann. Bot. 97: 461-467.

Hanelt, P. 1963. Monographische Übersicht der Gattung Carthamus L. (Compositae). Feddes Repert. Speci. Nova. Regn. Veget. 67: 41-180.

Harvey, B. L. and Knowles, P. F. 1965. Natural and artificial alloploids with 22 pairs of chromosomes in the genus Carthamus (Compositae). Can. J. Genet. Cytol. 7: 126-139.

Jayaramu, M. and Chatter, J. 1986. Karyological studies on Indian wild safflower: C. oxyyachantus. Caryologia G. Citol. Citosistematica Citogenet. 39: 179-184.

Khidir, M. O. and Knowles, P. F. 1970a. Cytogenetic studies of Carthamus species (Compositae) with 32 pairs of chromosomes. I. Intrasectional hybridization. Am. J. Bot. 57: 123-129.

— and - 1970b. Cytogenetic studies of Carthamus species (Compositae) with 32 pairs of chromosomes. II. Intersectional hybridization. Can. J. Genet. Cytol. 12: 90-99.

Knowles, P. F. 1958. Safflower. Adv. Agron. 10: 289-323.

— and Ashri, A. 1958. Wild safflower in California. California Agri. 12: 4-5.

Kumar, H., Singh, R. B. and Pillai, R. S. N. 1984. Induction of unreduced microspore formation in safflower. Egypt. J. Genet. Cyto. 13: 19-24.

Levan, A., Fredga, K. and Sandberg, A. 1964. Nomenclature for centromeric position on chromosomes. Hereditas 52: 201-220.

Nirmala, A. and Rao, P. N. 1996. Genetics of chromosome numerical mosaism in higher plants. Nucleus 39: 151-175.

Pillai, R. S. N., Kumar, H. and Singh, R. B. 1981a. Karyotype analysis of safflower. Crop Sci. 21: 809-811.

- - - and - 1981b. Translocation homozygotes in safflower. Crop Sci. 21: 815-818.

Rees, H. and Jones, R. N. 1977. Chromosome Genetics. Edward Arnold, London, pp 160.

Sheidai, M. and Inamdar, A. C. 1991. Variations in meiotic chromosomes in Asparagus L. Biovigyanum 17: 45-47.

— and Jalilian, N. 2008. Karyological studies of some species and populations of Lotus L. in Iran. Acta Bot. Croat. 67: $42-52$.

— and Rashid, S. 2007. Cytogenetic study of some Hordeum L. species in Iran. Acta Biol. Zseged. 51: 107-112.

Singh, R. B., Pillai, R. S. N. and Kumar, H. 1981. Induced translocations in safflower. Crop Sci 21: 811-815

Stebbins, G. L. 1971. Chromosomal Evolution In Higher Plants. Edward Arnold, London.

-, Garnatje, T., Susanna, A. and Garcia-Jacas, N. 2005. Taxonomic problems in Carthamus (Asteraceae): RAPD markers and sectional classification. Bot. J. Linn. Soci. 147: 375-383.

Vilatersana, R., Martín, J., Susanna, A., Garcia-Jacas, N. and Garnatje, T. 2000. Generic delimitation and phylogeny of the Carduncellus-Carthamus complex (Asteraceae) based on ITS sequences. Plant Syst. Evol. 221: 89-51. 